\title{
HUBUNGAN PENCAHAYAAN DENGAN KELUHAN SUBJEKTIF KELELAHAN KERJA PADA PEKERJA BAGIAN UNDERGROUND DI PT. ANTAM Tbk, UBPE PONGKOR BOGOR TAHUN 2018
}

\author{
Ani Minarni ${ }^{1)}$, Rubi Ginanjar ${ }^{2)}$, dan Anissatul Fathimah ${ }^{3)}$
}

\footnotetext{
${ }^{1)}$ Konsentrasi Kesehatan dan Keselamatan Kerja, Program Studi Kesehatan Masyarakat, Fakultas Ilmu Kesehatan Universitas Ibn Khaldun Bogor. E-mail : animinarni9@gmail.com

${ }^{2)}$ Program Studi Kesehatan Masyarakat, Fakultas Ilmu Kesehatan Universitas Ibn Khaldun Bogor E-mail : rubi.ginanjar@gmail.com

${ }^{3)}$ Program Studi Kesehatan Masyarakat, Fakultas Ilmu Kesehatan Universitas Ibn Khaldun Bogor E-mail : anissatulfathimah@gmail.com
}

\begin{abstract}
Abstrak
Kelelahan kerja merupakan kondisi dimana seseorang sudah tidak mampu lagi melalukan aktivitas kerjanya. Kelelahan keraj dapat terjadi karena adanya pengaruh dari lingkungan kerja yang tidak menunjang. Tujuan dari penelitian ini adalah untuk mengetahui hubungan pencahayaan serta karakteristik individu (umur, beban kerja dan status gizi) dengan kelelahan kerja pada pekerja bagian underground di PT.Antam Bogor. Metode penelitian ini adalah penelitian kuantitatif dengan desain penelitian menggunakan cross sectional. Populasi penelitian sebanyak 200 orang dan teknik pengambilan sampel menggunakan purposive sampling dengan jumlah sampel penelitian sebesar 67 responden. Pengukuran pencahayaan menggunakan alat lux meter dan pengumpulan data pekerja dilakukan dengan menggunakan kuesioner IFRC. Analisis data penelitian menggunakan aplikasi statistik dengan menggunakan uji statistik chi-square. Hasil analisis menunjukkan ada hubungan antara umur ( $p$-value $=0,044)$ OR sebesar 3,147 dan beban kerja ( $p$-value $=0,032)$ OR sebesar 3,407 dan tidak adanya hubungan antara pencahayaan $(p$-value $=0,937)$ dan status gizi $(p$-value $=0,601)$ dengan kelelahan kerja. Kesimpulan dari penelitian ini adalah tidak adanya hubungan pencahayaan dengan kelelahan kerja. Peneliti ini menyarankan kepada perusahaan untuk memperhatikan kondisi pencahayaan diruangan kerja agar tidak menimbulkan risiko terjadinya kelelahan kerja
\end{abstract}

Kata kunci: pencahayaan, kelelahan kerja, umur, beban kerja, status kerja

\section{Pendahuluan}

Kesehatan kerja merupakan salah satu bidang kesehatan masyarakat yang memfokuskan perhatian pada masyarakat pekerja baik yang berada di sektor formal maupun yang berada di sektor informal (Depkes RI, 2007). Kelelahan kerja adalah perasaan lelah dan adanya penurunan kegiatan oleh Grandjean dalam Setyawati (2010).

Faktor lingkungan yang menunjang tenaga kerja dalam keadaan sehat dan produktif harus adanya pencahayaan. Pencahayaan membantu manusia melihat lebih jelas dan lebih teliti dalam pekerjaannya. Pencahayaan merupakan suatu aspek lingkungan fisik yang penting bagi keselamatan kerja. Pencahayaan juga sangat berpengaruh terhadap produktivitas pekerja. Penerangan yang baik yaitu penerangan yang memungkinkan tenaga kerja dapat melihat objek yang dikerjakan dengan jelas dan juga 
dengan cepat tanpa upaya yang tidak perlu (Suma'mur PK, 2009).

Penelitian yang dilakukan oleh Setyowati (2014), menyebutkan bahwa kelelahan secara langsung dipengaruhi oleh stres kerja, konflik kerja, lingkungan fisik serta kapasitas kerja. Budiono (2008), mengatakan bahwa kelelahan ditandai dengan melemahnya tenaga kerja dalam melakukan pekerjaan atau kegiatan sehingga akan meningkatkan kesalahan dalam melakukan pekerjaan dan akibat fatalnya yaitu terjadinya kecelakaan kerja. Data dari International Labour Organitation (2013), menyebutkan sebanyak dua juta pekerja menjadi korban setiap tahun karena kecelakaan kerja akibat kelelahan. Penelitian yang dilakukan International Labour Organitation (2013), menjelaskan bahwa sebanyak 58.118 sampel dari 18.828 sampel $(32,8 \%)$ di antaranya mengalami kelelahan dan berpengaruh pada produktivitas kerja.

Pencahayaan adalah jumlah penyinaran pada suatu bidang kerja yang diperlukan untuk melaksanakan kegiatan secara efektif. Intensitas pencahayaan di tempat kerja dimaksudkan untuk memberikan pencahayaan

\section{Metode}

Jenis penelitian ini adalah penelitian observasional analitik dengan rancangan cross sectional. Rancangan penelitian cross sectional yaitu suatu penelitian untuk mempelajari dinamika korelasi antara faktorfaktor risiko dengan efek, dengan cara pendekatan, observasi atau pengumpulan data. (Notoadmodjo, 2010). Dalam penelitian ini, untuk mengetahui hubungan pencahayaan dengan keluhan subjektif kelelahan kerja pada pekerja bagian underground di PT. Antam Tbk, UBPE Pongkor Bogor Tahun 2018.

Penelitian di lakukan di PT. Antam Tbk, UBPE Pongkor Bogor, dengan melibatkan pekerja bagian underground. Waktu kepada benda-benda yang merupakan objek kerja, peralatan atau mesin dan proses produksi serta lingkungan kerja. Untuk itu diperlukan intensitas pencahayaan yang optimal.Selain menerangi objek kerja, pencahayaan juga diharapkan cukup memadai menerangi keadaan sekelilingnya (SNI 167062, 2004). Pencahayaan dapat diukur dengan menggunakan alat Lux Meter.

Peraturan Menteri Ketenagakerjaan Republik Indonesia Nomor 5 Tahun 2018 Tentang Keselamatan Dan Kesehatan Kerja Lingkungan Kerja pencahayaan yang diizinkan berdasarkan tingkat dan pencahayaan ditempat kerja adalah 50 Lux.

Berdasarkan hal tersebut peneliti ingin mengetahui hubungan pencahayaan dengan keluhan subjektif kelelahan kerja pada pekerja bagian underground di PT. Antam Tbk, UBPE Pongkor Bogor Tahun 2018.

pelaksanaannya pada bulan Juli 2018. Populasi pada penelitian ini adalah seluruh pekerja underground yang berjumlah 200 Karakteristik individu umur $\geq 40$ tahun lebih banyak yaitu sebanyak 36 pekerja $(53,7 \%)$, usia <40 tahun sebanyak 31 pekerja pekerja. Sampel yang diteliti pada penelitian ini adalah pekerja underground sebanyak 67 orang. Teknik pengambilan sampel yang digunakan yaitu nonprobability sampling.

Variabel dalam penelitian ini adalah pencahayaan, karakteristik individu (umur, beban kerja, status gizi) dan kelelahan kerja.

Data yang digunakan dalam penelitian ini yaitu primer yang merupakan data yang 
diperoleh secara langsung dari sumber data yang didapatkan dengan cara pengukuran

\section{Hasil}

Hasil analisis univariat pada hasil pencahayaan sebanyak 67 pekerja diketahui bahwa pencahayaan responden sebagian besar pencahayaan kurang dari 50 lux sebanyak 54 responden (80,6\%), sedangkan responden yang pencahayaan lebih dari 50 lux sebanyak 13 responden $(19,4 \%)$ dan kelalahan kerja hasil kelelahan kerja diketahui bahwa responden sebagian besar kelelahan sebanyak 29 responden $(43,3 \%)$, sedangkan responden pencahayaan menggunakan Lux Meter dan kuesioner.

yang tidak kelelahan sebanyak 38 responden $(56,7 \%)$. (46,3\%). Pekerja dengan beban kerja sedang 200-350 kkal/jam lebih banyak yaitu sebanyak 35 pekerja (52,2\%), beban kerja berat 350-500 kkal/jam sebanyak 32 pekerja $(47,8 \%)$. Pekerja dengan status gizi $(56,7 \%)$, status gizi $\geq 24 \mathrm{~kg}$ sebanyak 29 pekerja $(43,3 \%) .<24 \mathrm{~kg}$ lebih banyak yaitu sebanyak 38 pekerja

Tabel 1 Hubungan Pencahayaan dengan Kelelahan Kerja

Pada Pekerja Bagian Underground di PT. Antam Tbk, UBPE Pongkor Bogor Tahun 2018

\begin{tabular}{|c|c|c|c|c|c|c|c|c|}
\hline \multirow{3}{*}{ Pencahayaan } & \multicolumn{4}{|c|}{ Kelelahan Kerja } & \multirow{2}{*}{\multicolumn{2}{|c|}{ Total }} & \multirow[t]{3}{*}{ P-Value } & \multirow[t]{3}{*}{ OR $(95 \% \mathrm{CI})$} \\
\hline & \multicolumn{2}{|c|}{$\begin{array}{c}<35,72 \text { Tidak } \\
\text { Kelelahan }\end{array}$} & \multicolumn{2}{|c|}{$\geq 35,72$ Kelelahan } & & & & \\
\hline & $\mathrm{N}$ & $\%$ & $\mathrm{~N}$ & $\%$ & $\mathrm{~N}$ & $\%$ & & \\
\hline $\begin{array}{l}<50 \text { Lux } \\
\text { tidak } \\
\text { memenuhi } \\
\text { standar }\end{array}$ & 24 & 44,4 & 30 & 55,6 & 54 & 100 & & $1,280(0,371-4,421)$ \\
\hline $\begin{array}{l}\geq 50 \text { Lux } \\
\text { memenuhi } \\
\text { standar }\end{array}$ & 5 & 38,5 & 8 & 61,5 & 13 & 100 & 0,937 & \\
\hline Total & 29 & 43,3 & 38 & 56,7 & 67 & 100 & & \\
\hline
\end{tabular}

Hasil analisis bivariat (chi square) dalam tabel 1-2 diketahui tidak ada hubungan antara pencahayaan ( $p$-value $=0,937)$ dan status gizi $(p$-value $=0,601)$ dengan kelelahan kerja. Ada hubungan antara umur ( $p$ value $=0,044)$ dan beban kerja ( $p$ value $=0,032$ ) dengan kelelahan kerja. 
Tabel 2 Hubungan Pencahayaan dengan Kelelahan Kerja

Pada Pekerja Bagian Underground di PT. Antam Tbk, UBPE Pongkor Bogor Tahun 2018

\begin{tabular}{|c|c|c|c|c|c|c|c|c|}
\hline \multirow{3}{*}{$\begin{array}{c}\text { Karakteristik } \\
\text { Individu } \\
\end{array}$} & \multicolumn{4}{|c|}{ Kelelahan Kerja } & \multirow{2}{*}{\multicolumn{2}{|c|}{ Total }} & \multirow[t]{3}{*}{ P-Value } & \multirow{3}{*}{ OR $(95 \% \mathrm{CI})$} \\
\hline & \multicolumn{2}{|c|}{$\begin{array}{c}<35,72 \text { Tidak } \\
\text { Kelelahan }\end{array}$} & \multicolumn{2}{|c|}{$\geq 35,72$ Kelelahan } & & & & \\
\hline & $\mathrm{N}$ & $\%$ & $\mathrm{~N}$ & $\%$ & $\mathrm{~N}$ & $\%$ & & \\
\hline \multicolumn{9}{|l|}{ Umur } \\
\hline$<40$ tahun & 18 & 58,1 & $\overline{13}$ & 41,9 & 31 & 100 & \multirow{3}{*}{0,044} & \multirow[t]{3}{*}{$3,147(1,151-8,604)$} \\
\hline$\geq 40$ tahun & 11 & 30,6 & 25 & 69,4 & 36 & 100 & & \\
\hline Total & 29 & 43,3 & 38 & 56,7 & 67 & 100 & & \\
\hline \multicolumn{9}{|l|}{ Beban Kerja } \\
\hline $\begin{array}{l}\text { Sedang } 200- \\
350 \mathrm{kkal} / \mathrm{jam}\end{array}$ & 20 & 57,1 & 15 & 42,9 & 35 & 100 & \multirow{3}{*}{0,032} & \multirow[t]{3}{*}{$3,407(1,228-9,457)$} \\
\hline $\begin{array}{l}\text { Berat } 350- \\
500 \mathrm{kkal} / \mathrm{jam}\end{array}$ & 9 & 28,1 & 23 & 71,9 & 32 & 100 & & \\
\hline Total & 29 & 43,3 & 38 & 56,7 & 67 & 100 & & \\
\hline \multicolumn{9}{|l|}{ Status Gizi } \\
\hline $\begin{array}{l}<24 \mathrm{~kg} \\
\text { Normal } \\
\end{array}$ & 18 & $\overline{47,4}$ & 20 & 52,6 & 38 & 100 & \multirow{3}{*}{0,601} & \multirow[t]{3}{*}{$1,473(0,551-3,939)$} \\
\hline $\begin{array}{l}\geq 24 \mathrm{~kg} \\
\text { Overweight }\end{array}$ & 11 & 37,9 & 18 & 62,1 & 29 & 100 & & \\
\hline Total & 29 & 43,3 & 38 & 56,7 & 67 & 100 & & \\
\hline
\end{tabular}

\section{Pembahasan}

Berdasarkan tabel 1 tidak ada hubungan antara pencahayaan dengan kelelahan kerja pada pekerja bagian underground di PT. Antam Tbk, UBPE Pongkor Bogor. Penelitian ini sejalan dengan Ofin Andina Permata Sari (2016) menunjukkan bahwa tidak terdapat hubungan intensitas pencahayaan yang signifikan terhadap terjadinya kelelahan kerja. Nurlinda Anggraini (2011) bahwa tidak ada hubungan yang bermakna antara intensitas cahaya dengan kelelahan kerja, dikarenakan ritme kerja yang tidak menetap pada saat melakukan pekerjaan sehingga tingkat pencahayaan yang diperlukan pada saat melakukan pekerjaan yang berbeda-beda. Namum penelitian ini tidak sejalan dengan Septiana (2013) tentang kelelahan kerja yang dipengaruhi pencahayaan pada operator scarfing didapatkan hasil berupa terdapat hubungan pencahayaan dengan kelelahan kerja. Menurut Soeripto (2008) juga menjelaskan bahwa apabila intensitas pencahayaan tidak memadai (suram atau menyilaukan), maka dapat menyebabkan produktivitas tenaga kerja menurun atau menjadi rendah.

Berdasarkan tabel 2 responden yang menjadi obyek penelitian mayoritas berada diatas 40 tahun, namun berdasarkan hasil penelitian bahwa ada hubungan umur dengan kelelahan kerja pada pekerja bagian underground di PT. Antam Tbk, UBPE Pongkor Bogor. Penelitian ini sejalan dengan Malonda (2015) tentang hubungan antara umur, waktu kerja dan status gizi dengan kelelahan kerja pada tenaga kerja di bagian produksi PT. Sari Usaha Bitung yang menunjukkan hasil $\mathrm{p}=0,012(\mathrm{p}<0,05)$ yang artinya umur dengan kelelahan kerja memiliki hubungan yang signifikan. Kemudian pada penelitian Moch. Noval Mauludi (2010), di PT. Indocement Tunggal Prakarsa TBK yang menyatakan bahwa pekerja usia $>40$ tahun menunjukan $\mathrm{p}=0,035$ yang artinya ada hubungan antara umur dengan kelelahan kerja. Menurut Akerstedt, et al (2002) bahwa kelelahan lebih cenderung terjadi pada pekerja berumur kurang lebih sama dengan 49 tahun. 
Berdasarkan tabel 2 menunjukkan beban kerja bahwa ada hubungan dengan kelelahan kerja pada pekerja bagian underground di PT. Antam Tbk, UBPE Pongkor Bogor. Penelitian ini sejalan dengan penelitian Ihsan dan Rachmatiah (2015) pada pekerja di bagian Divisi Stamping PT. X bahwa terdapat hasil analisis statistic diperoleh adanya hubungan antara kelelahan kerja dengan beban kerja $(\mathrm{p}=0,000)$ di Divisi Stamping PT. X.Kemudian pada penelitian Maulina (2011) tentang Pengaruh Beban Kerja Terhadap Kelelahan Kerja pada Pekerja Linting Manual di PT. Djitoe Indonesia Tobacco Surakarta bahwa didapatkan ada pengaruh beban kerja terhadap kelelahan kerja pada pekerja dengan nilai $p=0,000$. Penelitian yang dihasilkan Jannah (2014) diperoleh $p$ value sebesar $0,033<p(0,05)$ dimana terdapat hubungan signifikan antara beban kerja dengan kelelahan kerja pada karyawan bagian cutting PT. Dan Liris Banaran Kabupaten Sukoharjo. Namun penelitian ini berbeda dengan penelitian yang dilakukan oleh Venny Mariyani (2017) menunjukkan bahwa tidak ada hubungan kelelahan kerja dengan responden yang mengalami beban kerja ringan dan responden yang mengalami beban kerja sedang. Seseorang akan menerima beban kerja dari aktivitas pekerjaan yang dilakukannya, ketika waktu kerja bertambah maka beban kerja pun akan bertambah karena beban kerja tersebut dapat melebihi batas kemampuan seseorang

\section{Kesimpulan}

Dari penelitian ini dapat disimpulkan bahwa:

1. Gambaran pencahayaan, umur, beban kerja dan status gizi dengan kelelahan kerja : Intensitas pencahayaan <50 lux sebanyak $54(80,6 \%), \geq 50$ lux sebanyak $13(19,4 \%)$. Umur : $<40$ tahun sebanyak $31(46,3 \%), \geq 40$ tahun sebanyak 36 $(53,7 \%)$. Beban kerja : sedang 200-350 dalam bekerja yang menimbulkan kelelahan kerja (Suma'mur, 2009).

Berdasarkan tabel 2 menunjukkan status gizi dan tidak ada hubungan hubungan umur dengan kelelahan kerja pada pekerja bagian underground di PT. Antam Tbk, UBPE Pongkor Bogor. Penelitian ini sejalan dengan penelitian kelelahan pada pekerja proyek dimana pada tingkat kelelahan sedang, dari 65 pekerja dengan status gizi normal, 25 pekerja $(38,5 \%)$ mengalami kelelahan sedang. Sedangkan dari 35 pekerja dengan status gizi tidak normal, 20 pekerja $(57,1 \%)$ mengalami kelelahan sedang. Hal ini berarti tidak dapat 127 ditemukan adanya hubungan yang bermakna antara status gizi dengan kelelahan pada pekerja (Marif, 2013). (Gunawan, 2011) pada pekerja perawat di Rumah Sakit Siloam bahwa terdapat hasil analisis statistic diperoleh adanya tingkat hubungan sedang antara kelelahan kerja dengan status gizi. Penelitian yang menemukan adanya hubungan antara status gizi dengan kelelahan kerja langgar, dkk (2014) mengenai hubungan antara asupan gizi dan status gizi dengan kelelahan kerja pada karyawan perusahaan Tahu Baxo $\mathrm{Bu}$ Pudji di Unggaran dan penelitian yang dilakukan oleh Herliani (2012) mengenai hubungan status gizi dengan kelelahan kerja pada pekerja insudtri pembuatan gamelan di daerah wirun sukoharjo yang mengatakan bahwa terdapat hubungan antara status gizi dengan kelelahan kerja.

$\mathrm{kkal} / \mathrm{jam}$ sebanyak 35 (52,2\%), beban kerja berat 350-500 kkal/jam sebanyak 32 responden $(47,8 \%)$. status gizi: $<24$ normal sebanyak $38(56,7 \%), \geq 24$ overweight sebanyak $29 \quad(43,3 \%)$. kelelahan kerja: kelelahan sebanyak 29 $(43,3 \%)$, tidak kelelahan sebanyak 38 responden $(56,7 \%)$. 
2. Tidak ada hubungan antara pencahayaan dengan kelelahan kerja pada pekerja underground. Hal ini disebabkan karena tempat kerja bagian underground terdapat pencahayaan yang kurang dari 50 lux.Tempat kerja bagian underground memiliki terowongan yang sangat gelap dan hanya ada cahaya buatan yaitu lampu neon yang dipasang dengan jarak 20 meter.Selain lampu neon adapun pencahayaan lampu headlamp yang bisa membantu para pegawai bekerja dengan cahaya buatan tanpa adanya cahaya alami.

3. Ada hubungan antara umur dengan kelelahan kerja pada pekerja underground. Hal ini terjadi karena jenis kegiatan pekerjaan dan tempat bekerjanya pegawai di bagian underground yang kurangnya suhu udara dan kadar oksigen menipis dapat menyebabkan dehidrasi dan konsentrasi kurang pada pekerja maka mengalami kelelahan kerja pada pekerja.

4. Ada hubungan antara beban kerja dengan kelelahan kerja pada pekerja underground. Hal ini dipengaruhi karena tempat kerja yang berlokasi dibawah tanah dengan suhu udara yang kurang dan kadar oksigen menipis maka para pekerja dapat menyebabkan beban kerja dengan kelelahan kerja.

5. Tidak ada hubungan antara status gizi dengan kelelahan kerja pada pekerja underground. Hal ini disebabkan karena pola makan pekerja sudah teratur dengan baik dan mendapatkan makanan yang gizi seimbang, menu yang didapatkan oleh pekerja yaitu nasi, tempe, sayuran dan lauk pauk. Oleh karena itu tidak terdapat hubungan antara status gizi dengan kelelahan kerja karena pekerja memiliki status gizi yang normal dan seimbang. 


\section{Daftar Pustaka}

[1] Andina Ofin, Permata Sari. 2016. Hubungan Lingkungan Kerja Fisik dengan Kelelahan Kerja pada Kolektor Gerbang Tol Cililitan PT. Jasa Marga Cabang Cawang Tomang Cengkareng. Skripsi. Fakultas Kedokteran dan Ilmu Kesehatan Universitas Islam Negeri Syarif Hidayatullah.

[2] Depkes RI. 2007. Kesehatan dan Keselamatan Kerja. Jakarta: depkes RI.

[3] Herliani, F. 2012. Hubungan Status Gizi dengan Kelelahan Kerja Pada Pekerja Industri Pembuatan Gamelan di Daerah Wirun Sukohardjo. Jurnal diakses pada tanggal 27 maret 2017.

[4] Internasional Labour Organisation. 2013. Data Kecelakaan Akibat Kerja.

[5] Made Ayu Sawitri, Grace D. Kandou, dan Rahayu H. Akili. 2017. Hubungan antara Intensitas Pencahayaan dan Usia dengan Kelelahan pada Pekerja Bagian Operasional PT. Angkaasa Pura I (Persero) Kota Manado. Jurnal
Kesehatan Masyarakat Universitas Sam Ratulangi Manado.

[6] Mauludin, MN. 2010. Faktor-faktor yang berhubungan dengen kelelahan pada pekerja diproses produksi kantong semen PBD (Paper Bag Division) PT. Indocement Tunggal Prakarsa TBK. Citeureup Bogor Tahun 2010. Jurnal diakses pada tanggal 24 Mei 2016.

[7] Notoadmodjo, Soekidjo. (2010). Metodologi Penelitian Kesehatan. Jakarta: Rineka Cipta

[8] Setyawati L. 2010. Selintas Tentang Kelelahan Kerja. Yogyakarta : Amara Books.

[9] Standar Nasional Indonesia SNI 167062-2004 Pengukuran Intensitas Penerangan di Tempat Kerja. 